\title{
Reflexiones jurídicas acerca de la posverdad
}

Legal and Philosophical Reflections on Post-truth

\author{
Juan Manuel de Faramiñán Fernández-Fígares \\ Universidad de Granada \\ faraminan@maatasesores.com
}

Resumen: En este artículo se analiza la naturaleza conceptual de la posverdad con objeto de delimitar y, por lo tanto, identificar, los factores que la alimentan. Para ello, considerando su definición, se especifican cuáles son sus principales canales de información y se constata cómo el recabado masivo de datos se está convertido en una peligrosa amenaza. Frente a ello, se señala cual es actualmente su regulación jurídica y se realizan algunas propuestas, tanto jurídicas como filosóficas, con la intención de contribuir al debate sobre el estado de esta cuestión.

Palabras clave: posverdad, derecho, filosofía, protección de datos, información.

Abstract: This article discusses the conceptual nature of posttruth I order to delimit and, therefore, identify, the factors that feed it. To do this, considering its definition, its main channels of information are specified and it is confirmed how massive data collection is becoming a dangerous threat. Against this, it is 
indicated what is currently its legal regulation and some proposals are made, both legal and philosophical with the intention of contributing to the debate on the status of this issue.

Keywords: post-truth, law, philosophy, data protection, information.

Fecha de recepción: $27 / 7 / 2020$ Fecha de aceptación: 17/2/2021 


\section{Introducción}

Para poder regular de manera conveniente el fenómeno de la posverdad urge delimitar y controlar antes los factores que la alimentan, pues la posverdad se ha convertido hoy en una nueva Hidra con tantas cabezas, que a menudo resulta imposible adivinar cuál es el cuerpo que las sostiene y las sustenta. Su nefasta influencia pasa desapercibida ante nuestros ojos con el disfraz de una realidad a la que pocas veces se remite, pero a la que en todos los casos condiciona. Con su voz profunda y atávica ha aprendido a activar los resortes inconscientes de la sociedad y pocos son los que de manera voluntaria saben escapar a su influjo. Así las cosas, ha desarrollado vida propia y, como muchas otras creaciones humanas, ha terminado por someter a aquellos que le insuflaron la vida.

Llegados a este punto, se hace necesario analizar esta figura escudriñando sus raíces en la tierra, con objeto de poder identificar y limitar la sabia nutricia que, como a Anteo, la reaviva e impulsa. Para ello, el primer escollo que tenemos que salvar se encuentra en su etimología, pues, al hacer referencia a un concepto tan ambiguo y relativo como la verdad, deja abiertos un sinfín de caminos interpretativos por los que se diluye cada vez que alguien trata de acotar sus efectos. Sin embargo, si atendemos a su definición y significado, a pesar del origen relativamente nuevo del concepto, podemos encontrar un elemento que nos permite identificarla por encima de sus infinitas apariencias. Esta peculiaridad es el carácter emotivo que la posverdad imprime a sus efectos y que escapa, por definición, al filtro de la razón y el en- 
tendimiento ${ }^{1}$. Se trata de un requisito anímico y emocional que alcanza incluso, trastocándolo, al ámbito de las creencias, ya que al apoyarse estas últimas en el carácter universal de una verdad, resulta relativamente fácil manipularlas cuando se dispone del control de los actuales medios de difusión de «la verdad».

La naturaleza emocional de la posverdad nos acerca entonces a uno de sus principales sustratos, el conocimiento científico y especulativo de las funciones del ánimo y la psique y su aplicación espuria con fines comerciales y propagandísticos. Una disciplina que ha derivado del campo de la psicología y que se ha hecho fuerte en otros ámbitos más discutibles como son los del comercio y la industria de la desinformación ${ }^{2}$. Aunque su origen se oculta entre los pliegues del siglo que nos precede, su alcance hoy es cada vez mayor gracias a los nuevos medios de obtención de datos con los que cuenta, pues, en efecto, como en toda ciencia, su conocimiento depende de su capacidad de recabar referencias para sus análisis. La venta de información y el uso masivo de datos se han convertido así en las herramientas más eficaces para el conocimiento de las emociones y el comportamiento del ser humano. Una rama de estudio que ya no tiene como objeto la mejora y el desarrollo del individuo, sino su control absoluto y la búsqueda de estímulos suficientes que lo conviertan en un modelo aceptable de ciudadano para nuestra moderna sociedad de consumo.

Cabe advertir que esta pérdida de libertad, precio y consecuencia del vertiginoso modo de vida actual (siempre dispuesto al cambio) se ha travestido bajo la dócil apariencia del progreso y el desarrollo. El bienestar y la comodidad, artificios de necesidad

1 Según el Diccionario de la RAE, la posverdad es la: «Distorsión deliberada de una realidad, que manipula creencias y emociones con el fin de influir en la opinión pública y en actitudes sociales». 2 A este respecto recomendamos el análisis audiovisual de las estrategias de desinformación de doce de los partidos europeos más importantes de la extrema derecha a través de YouTube realizado por Rodríguez-Serrano, García-Catalán y Martín-Núñez (2019: 1-10).

Faramiñán Fernández-Fígares, Juan Manuel de (2021). «Reflexiones jurídicas acerca de la posverdad». Monograma. Revista Iberoamericana de Cultura y Pensamiento, n. ${ }^{\circ}$ 8, pp. 59-78. doi: 10.36008/monograma.2021.08.1508. http: revistamonograma.com. ISSN: 2603-5839. 
que nunca llegan a satisfacerse por completo, son sus señuelos y, como si los medios hubieran usurpado su lugar natural a los fines, han conseguido traspasar las frágiles fronteras de la intimidad subyugando al ser humano a sus propios instintos. De manera ingenua e inocente nos hemos convertido en esclavos de nosotros mismos y, espoleados por una cada vez mayor mercantilización de la vida, asignamos más valor a las formas que a las esencias. Las apariencias se erigen de este modo en destellos fugaces de realidad que estimulan nuestros variables deseos y apetitos, y nada tiene más importancia que la novedad o la mórbida satisfacción que produce el dolor cuando es ajeno.

La cuestión de fondo es filosófica y deviene en parte de la absoluta pérdida de sentido vital que han producido los viejos dogmas y promesas del pasado, que con su fracaso han dejado a la humanidad huérfana de raíces y criterios morales y que, aún hoy, persisten en aleccionar y adoctrinar en lugar de educar y formar a los seres humanos para que puedan ser más ellos mismos. Sin embargo, su efecto directo es jurídico y demanda para su delimitación una regulación urgente en todos los ámbitos, comenzando por la regulación de la información que es susceptible de ser utilizada con fines ilegítimos. Para ello, deberíamos empezar por distinguir y separar las necesidades inherentes a todo individuo — como son el derecho a la intimidad, al libre desarrollo de la personalidad o a ser considerado como un fin en sí mismo y no como un medio- de aquellas necesidades sintéticas y engañosas con las que sin querer nos sometemos los unos a los otros, tales como la comodidad, el bienestar o la opinión de los demás.

Partiendo de esta diferenciación apriorística, la cuestión de la constante cesión de datos e información, en la que nos estamos sumergiendo cada vez más, cobra una dimensión especial, pues es tal el desconcierto generalizado en la sociedad que apenas se 
intuyen sus consecuencias futuras. Nadie es capaz de anticiparse con exactitud a qué tipo de futuro nos enfrenta un entorno en el que la minería masiva de datos o big data ha desbancado ampliamente a la estadística, en el que el análisis de la información es capaz de convertir los resultados en certezas casi absolutas y en el que el conocimiento de los aspectos pasionales del ser humano ha llegado hasta el punto de poder anticipar y condicionar el desenlace de un proceso digamos «democrático» ${ }^{3}$.

$\mathrm{Y}$ es que, a merced de falsas necesidades domésticas, estamos convirtiendo nuestros hogares en complejos dispositivos de gestión de datos que recaban diariamente grandes cantidades de información sensible y susceptible de ser manipulada. Nos hemos convertido en ciudadanos de cristal, «tan trasparentes como frágiles» ${ }^{4}$. La justificación es siempre la misma y parte de la viciada visión egocéntrica que caracteriza al hombre y a la mujer contemporáneos que no consideran importante pagar este precio a cambio de pequeñas y breves satisfacciones que se han convertido en cotidianas. Sin embargo, a menudo se olvida el alcance colectivo que toda esa información puede llegar a tener cuando se analiza de forma conjunta con la intención de manipular de forma masiva a la sociedad ${ }^{5}$. Tal es el caso de la

\footnotetext{
3 Para Cristina Pauner (2018: 299), «El peligro de las noticias falsas es que crean una sociedad que no es capaz de ponerse de acuerdo sobre hechos básicos lo que impide construir una democracia funcional. La desinformación afecta directamente a los fundamentos de las sociedades democráticas que se construyen sobre la presunción de que sus ciudadanos toman decisiones informadas en el momento de acudir a votar».

4 Un término que también hace referencia a la pérdida de intimidad que deviene de un mal uso de la información por parte del Estado y sus Instituciones (Tejerina, 2014: 361-359).

5 Sin ir más lejos a través del filtrado personalizado de información que realizan los propios buscadores de internet con base en nuestros gustos personales y que, como denuncia Pauner (2018: 303), hace que «la versión del mundo que encontramos a diario solo sirva para confirmar y reafirmarnos en nuestras creencias preexistentes gracias a la limpieza invisible a la que ha sido sometida. [...] Esas fórmulas deciden lo que es visible para nosotros y lo que nos va a permanecer oculto limitando nuestro conocimiento de un más amplio abanico de ideas e información fidedigna y condicionando el descubrimiento casual de otras fuentes de conocimiento».
}

Faramiñán Fernández-Fígares, Juan Manuel de (2021). «Reflexiones jurídicas acerca de la posverdad». Monograma. Revista Iberoamericana de Cultura y Pensamiento, n. ${ }^{\circ}$ 8, pp. 59-78. doi: 10.36008/monograma.2021.08.1508. http: revistamonograma.com. ISSN: 2603-5839. 
posverdad, una nueva forma de control social y político que con su influjo está perforando los ya de por si desgastados cimientos de la confianza humana. Vuelven así los fanatismos y las actitudes viles que el miedo y la confusión despiertan en los corazones, y la falta de sentido común y de humanidad se tornan en los vástagos bastardos de nuestra falta de libertad interior.

Cabe por tanto hablar de derecho y de filosofía cuando nos encontramos ante tan aciago panorama, ya que la posverdad no es más que el resultado de nuestro mundo. Una consecuencia de nuestro desmedido modo de vivir que solo una regulación jurídica-formal y una formación profunda y filosófica de fondo puede corregir. En este sentido, el derecho puede ayudarnos a liberarnos —al limitarlos - de los efectos que la posverdad produce en nuestro entorno, mientras que la filosofía puede permitirnos liberarnos - al equilibrarlos - de nuestras propias aspiraciones y deseos. Así, mediante una correcta estructura jurídica podríamos restringir y controlar las vías que alimentan a la desinformación, acotando la información más sensible que es susceptible de ser manipulada. Al mismo tiempo, y gracias al correcto desarrollo y libre formación de la personalidad que proporciona la filosofía, podemos conseguir no depender tanto de la comodidad y el bienestar, al menos como para no estar dispuestos a pagar cualquier precio por ellos, ya sea este el de nuestra intimidad o el del hecho de que, para disfrutarlos, tengamos que cerrar muchas veces los ojos a la evidente falta de equilibro sobre la que se apoyan.

\section{Derecho y posverdad}

Hasta el momento, en España el derecho ha tratado de regular el uso responsable de nuestros datos y el acceso a la información de carácter sensible y personal a través de la Ley Orgánica

Faramiñán Fernández-Fígares, Juan Manuel de (2021). «Reflexiones jurídicas acerca de la posverdad». Monograma. Revista Iberoamericana de Cultura y Pensamiento, n. ${ }^{\circ}$ 8, pp. 59-78. doi: 10.36008/monograma.2021.08.1508. http: revistamonograma.com. ISSN: 2603-5839. 
de Protección de Datos y, sobre todo, de su correspondiente Reglamento General de desarrollo recientemente aprobado en 2016. Sin embargo, esta regulación, que se apoya en gran medida en la figura del consentimiento ${ }^{6}$, ha resultado ser insuficiente como para poder cubrir el extenso territorio que han abierto tras su paso las nuevas tecnologías basadas en internet. Por no decir que a menudo el hecho de que un usuario preste su consentimiento no es óbice como para considerar que sea plena y absolutamente consciente de sus consecuencias.

Este es un problema que tradicionalmente la ley ha resuelto haciendo responsable al sujeto de sus propios actos y considerando que el desconocimiento de las leyes no exime de su cumplimiento $^{7}$, pero que ahora, con un nuevo ecosistema digital que crece de manera vertiginosa, coloca al ciudadano en una clara situación de indefensión ante las novedosas e indirectas técnicas de recabado de datos e información. Las farragosas políticas de privacidad que la ley exige aceptar a los usuarios para poder hacer uso de determinados productos o servicios no han ayudado a facilitar un verdadero conocimiento del contrato jurídico que

\footnotetext{
6 Como apunta Ofelia Tejerina (2014: 40-42 y 96) citando la STC 11/1998 (F. J. ${ }^{\circ}$ 6. $^{\circ}$ ) y la STC 292/2000 F. J. ${ }^{\circ}$ 5. $^{\circ}$ respectivamente, la figura del consentimiento expreso en el ámbito de la protección de datos y el nacimiento de la Ley Orgánica de Protección de Datos Personales 15/1999 (LOPD) y de la Agencia Española de Protección de Datos para resolver los conflictos en los que este derecho sea menoscabado, tiene su origen en la ley Orgánica 5/1992, de 29 de octubre de Regulación del Tratamiento Automatizado de los Datos de Carácter Personal (LORTAD) y en la lectura que hace el Tribunal Constitucional del artículo 18.4 de la Constitución Española como «un instituto de garantía, pero también un instituto que es en sí mismo un derecho o libertad fundamental, el derecho a la libertad frente a las potenciales agresiones a la dignidad y a la libertad de la persona provenientes de un uso ilegítimo del tratamiento mecanizado de datos, lo que la Constitución llama "la informática"; lo que se llamó en su momento "libertad informática" (SSTC 143/1994 F. J. ${ }^{\circ} 7 .^{\circ}, 11 / 1998$ F. J..$^{\circ} 4{ }^{\circ}$, 9 94/1998 F. J. ${ }^{\circ}$ 6. ${ }^{\circ}$, 202/1999 F. J. ${ }^{\circ}$ $\left.2^{\circ} .^{\circ}\right)$, y que debía considerarse como el «derecho a controlar el uso de los mismos datos insertos en un programa informático (habeas data) y comprende, entre otros aspectos, la oposición del ciudadano a que determinados datos personales sean utilizados para fines distintos de aquel legítimo que justificó su obtención».

7 Artículo 6 del Código Civil.
}

Faramiñán Fernández-Fígares, Juan Manuel de (2021). «Reflexiones jurídicas acerca de la posverdad». Monograma. Revista Iberoamericana de Cultura y Pensamiento, n. ${ }^{\circ}$ 8, pp. 59-78. doi: 10.36008/monograma.2021.08.1508. http: revistamonograma.com. ISSN: 2603-5839. 
hay detrás, toda vez que las mismas redes que suministran los servicios demandados son las encargadas de recabar estos para financiarse y monetizar su actividad. Las novedosas políticas de cookies, que de nuevo se centran en la figura del consentimiento y cuyo objetivo visible es el de facilitar la navegación de los usuarios, tampoco han resuelto el riesgo que se deduce de su objetivo invisible, esto es, el de recabar datos para su comercialización.

La propuesta de Reglamento del Parlamento Europeo y del Consejo sobre el respeto a la vida privada y la protección de los datos personales en el sector de las comunicaciones electrónicas (Reglamento sobre la privacidad y las comunicaciones electrónicas o Reglamento ePrivacy) que deroga a la anterior Directiva 2002/58/CE, sí parecer haberse hecho eco de estas nuevas necesidades. Así, ha resuelto complementar al actual Reglamento General sobre la Protección de Datos como lex specialis ampliándolo en todo aquello que se refiere a las nuevas formas de comunicación digital y de recabado de datos. Por ello, en su artículo 5 establece de manera general que «estará prohibida cualquier interferencia con datos de comunicaciones electrónicas como, por ejemplo, la escucha, el pinchado, el almacenamiento, el seguimiento, el análisis u otros tipos de interceptación, vigilancia o tratamiento de datos de comunicaciones electrónicas, por parte de personas distintas a los usuarios finales».

Para el caso de las cookies, la propuesta mejora la figura del consentimiento recogida en su artículo 9 con la protección de la información almacenada en los equipos terminales de los usuarios finales y relativa a dichos equipos (art. 8) y la posibilidad de configurar las opciones de privacidad directamente en los equipos y programas informáticos (art. 10). Estos artículos, junto al número 6 del mismo texto, son los que más reticencias plantean a nivel gubernamental para su aprobación definitiva, no tanto 
por sus restricciones como por su falta de ellas, tal y como pone de manifiesto la respuesta del Gobierno Alemán 19/11351 de 3 de julio de 2019. A nivel comercial, sin embargo, sus detractores son aún más críticos y consideran que este Reglamento perjudica a los consumidores europeos, bloquea la economía en internet y paraliza sectores enteros como son las editoriales online o los medios y comunidades de servicios digitales. Así, denuncian que la nueva regulación limita la actual variedad de medios y aplicaciones en línea que están financiados por la publicidad forzando a que su uso y disfrute solo pueda ser posible mediante el pago y las tarifas personalizadas ${ }^{8}$.

En cualquier caso, este Reglamento puede suponer un avance en este campo, pues sienta un interesante precedente para futuras mejoras normativas. Esta regulación deberá aprender a moverse entre los inciertos límites que tanto el derecho a la información como a la libre prestación de servicios contrapone respecto del derecho a la intimidad, el secreto de las comunicaciones y al uso libre e inequívoco del consentimiento. De ahí que no sea casual que el propio Reglamento prevea, en el artículo 28 de sus Disposiciones Finales, su posible evaluación y revisión cada tres años con el pretexto de establecer su seguimiento y adecuación a las necesidades reales de un entorno digital que se encuentra en permanente cambio y desarrollo. Un propósito con el que esperemos que la Unión Europea sea capaz de armonizar la sempiterna oposición entre el orden, el control y la libertad sin menoscabar ni al uno ni al otro.

\footnotetext{
8 Una campaña liderada, entre otras, por las siguientes asociaciones y federaciones europeas: European Publishers Association, European Association of Communications Agencies, Association of Television and Radio Sales Houses, European Magazine Media Association, European Newspaper Publishers Association, Federation of European Direct and Interactive Marketing, Interactive Advertising Bureau Europe, World Federation of Advertisers, Association of European Radios, Association of Commercial Television in Europe.
}

Faramiñán Fernández-Fígares, Juan Manuel de (2021). «Reflexiones jurídicas acerca de la posverdad». Monograma. Revista Iberoamericana de Cultura y Pensamiento, n. ${ }^{\circ}$ 8, pp. 59-78. doi: 10.36008/monograma.2021.08.1508. http: revistamonograma.com. ISSN: 2603-5839. 
Cabe puntualizar que las normativas descritas hasta ahora regulan las actividades lícitas en el marco de la cesión de datos y el recabado de información, es decir, demarcan las prohibiciones bajo la idea general del compliance o garantía de cumplimiento normativo empresarial. Sin embargo, existe también todo un haz normativo que trata de identificar todas aquellas acciones que tienen lugar al margen de la legalidad, una forma de derecho punitivo que pretende remarcar los límites penales, no solo del uso criminal de estos datos, sino de su uso y abuso comercial. Tal es el caso del Código español de Derecho de la Ciberseguridad en el que se encuentran, entre otras, normas legales como el Real Decreto-Ley 12/2018 de 7 de septiembre de seguridad en las redes y sistemas de la información o, a nivel europeo, la Directiva 2016/1148 y la Ley de Seguridad Cibernética, que marcan la medida y alcance de las políticas de seguridad que deben proporcionar a sus ciudadanos los Estados miembros. Pero todas estas normas se centran sobre todo en conductas con un marcado carácter criminal y económico en el que, por el momento, no entra el servir de base a la posverdad.

En cuanto a la posverdad, su presencia jurídica es todavía mucho más escasa e insuficiente y plantea aún muchas dudas y reticencias en cuanto a sus límites y regulación. La razón de ello se encuentra de nuevo en el riesgo que una legislación excesivamente restrictiva puede suponer para la libertad de expresión e información. Aquí los medios más críticos se centran en el peligro del carácter masivo de esta conducta, pues si se mantiene dentro del ámbito doméstico y circunstancial no deja de ser una parte mejorable, aunque inherente de la naturaleza humana en su uso de la libertad de expresión, pero, cuando es aplicada por los grandes monopolios informativos, políticos y económicos, adquiere un cariz infeccioso que se permite propagarse con 
suma facilidad y eficacia. Un argumento que establece y parte de una equivalencia entre estos dos derechos constitucionales - que se diferencian entre sí tanto en grado como en categoría- y los delimita únicamente con base en una diferenciación cuantitativa, obviando, por desconocimiento, su relevancia cualitativa (Corredoira y Sánchez, 2017: 20-21). Y es que el derecho a la información conlleva una serie de exigencias que, si bien no tiene por qué limitar a los interlocutores, los sitúa en una situación de especial relevancia que, para su correcta realización, demanda la aplicación de una serie de principios básicos como son la relevancia pública y que la información sea veraz?

El problema de base es, empero, terminológico y deviene del hecho de que jurídicamente el concepto de posverdad no ha sido nunca contemplado como tal ${ }^{10}$. El carácter emocional de su tipología lo hace estar a caballo entre los delitos de injuria y calumnia - recogidos en nuestro Código Penal bajo la rúbrica de delitos contra la verdad (artículos 205, 208, 211, 212 y 215) - y los delitos de manipulación de las personas (concretamente los artículos 510.1 y 515), pero ninguno de estos artículos recoge exprofeso una reglamentación jurídica con respecto a un posible delito de posverdad, por lo que todos ellos evidencian lagunas a la hora de estipular las consecuencias jurídicas de esta actividad.

9 Como establece el Tribunal Constitucional en reiterada jurisprudencia (SSTC 6/1988, 20/1990, 105/1990,178/1993,133/1995 o 6/1996, cuando el artículo 20.1.d) de la CE establece el requisito de que la información sea veraz «no está tanto privando de protección a las informaciones que puedan resultar erróneas —o sencillamente no probadas en juicio—cuando estableciendo un específico deber de diligencia sobre el informador, a quien se le puede y debe exigir que lo que transmita como 'hechos' haya sido objeto de previo contraste con datos objetivos, privándose, así, de la garantía constitucional a quien, defraudando el derecho de todos a la información, actúe con menosprecio de la veracidad o falsedad de lo comunicado». STC 6/1988.

10 Por ejemplo, las únicas sentencias que, por el momento se han hecho eco de este neologismo de manera muy superficial son: la Sentencia de la Audiencia Provincial de Tenerife SAP TF 117/2018 de 19 de febrero de 2018 y, sobre todo, la reciente Sentencia del Tribunal Superior de Justicia (Sala de lo Social) de Santa Cruz de Tenerife STSJ ICAN 484/2019 de 19 de marzo de 2019.

Faramiñán Fernández-Fígares, Juan Manuel de (2021). «Reflexiones jurídicas acerca de la posverdad». Monograma. Revista Iberoamericana de Cultura y Pensamiento, n. ${ }^{\circ}$ 8, pp. 59-78. doi: 10.36008/monograma.2021.08.1508. http: revistamonograma.com. ISSN: 2603-5839. 
En este sentido, uno de los problemas de los delitos de calumnia e injuria es que dejan de considerarse como tales cuando se demuestra que la acusación versa sobre hechos reales, algo que supone una afirmación lo suficientemente ambigua como para no poder responder eficazmente a la cada vez más indeterminada desinformación que promueven los medios de comunicación masiva. Al mismo tiempo, el carácter individualista y singular de su redacción deja abierta una peligrosa compuerta en el ámbito de lo colectivo (de Faramiñán, 2019: 361-362).

Tampoco la Constitución Española nos da una respuesta suficiente a este respecto, pues su natural determinación a garantizar unos derechos mínimos e inalienables entra en contradicción cuando el derecho a la libertad de expresión y el derecho a recibir una información veraz (artículo 20.1) se encuentran de frente con el derecho al honor y a la intimidad de las personas de las que supuestamente se informa o se habla (artículo 18.1).

Hasta el momento, el Tribunal Constitucional, ha tendido a hacer prevalecer los primeros sobre los segundos, por lo que el derecho a la tutela judicial efectiva (artículo 75) se ha visto condicionado por una propensión a reivindicar la libertad de expresión e información como uno de los pilares de la sociedad libre y democrática $^{11}$. De nuevo aquí encontramos la condición de que los hechos noticiables deban guardar relación con la veracidad, aunque aquí se incluye, además, el requisito de que los hechos sean de interés general y de relevancia pública (STC 68/2008). No se regulan, sin embargo, los efectos que estas noticias pudieran tener, por su contenido emocional, en la opinión pública y las actitudes sociales.

Ni que decir tiene que este último requisito ha resultado ser un cajón de sastre en el que, a menudo, el ambiguo interés gene-

11 Por ejemplo, STC: 6/1981, 178/1993, 320/1994, 154/1999, 68/2008, 547/2011.

Faramiñán Fernández-Fígares, Juan Manuel de (2021). «Reflexiones jurídicas acerca de la posverdad». Monograma. Revista Iberoamericana de Cultura y Pensamiento, n. ${ }^{\circ}$ 8, pp. 59-78. doi: 10.36008/monograma.2021.08.1508. http: revistamonograma.com. ISSN: 2603-5839. 
ral se ha difuminado con la simple curiosidad del que la 'siempre sensible’ opinión pública está cada vez más ávida. Un campo en el que la posverdad ha abierto una veta de enorme productividad económica que supera con creces las ridículas indemnizaciones con las que se condena a los infractores. Algo más específica es la Ley Orgánica de protección civil del derecho al honor, a la intimidad personal y familiar y a la propia imagen de 1982, pero en ella nada se dice de su alcance colectivo ni, por supuesto, de las consecuencias sociales que pueden derivarse de una información tergiversada cuando el sujeto es indeterminado.

Por todo ello, a pesar del peligro que una regulación jurídica in extenso de la posverdad y las fake news ${ }^{12}$ puede suponer para las libertades públicas, no podemos considerar suficiente la normativa actual, toda vez que esta deja abiertas numerosas lagunas y vías de realización para este fenómeno tan dañino como poco novedoso. $\mathrm{Y}$ es que, aunque su alcance es hoy superior al que habría podido tener en cualquier otro momento de la historia, no se trata de una nueva tipología delictiva (Rubio, 2018: 203). Si se ha convertido, no obstante, en una nueva arma de manipulación social y política que ya ha alcanzado a todas las facciones e ideologías en las que la sociedad se divide, por lo que su control no puede dejarse solo en manos de los gobiernos, sino que, una vez más, demanda una actitud activa por parte de la ciudadanía. Esta puede y debe exigir mayor transparencia por parte de los Estados e interlocutores internacionales para que determinen una mayor claridad en todos los ámbitos susceptibles de ser regulados. Tal es el caso del concepto que nos ocupa y de su fuente principal de información. De ahí que consideremos oportuno

12 Como señala Rafael Rubio (2018: 198), «en el plano teórico se distinguen las "fake news", producción deliberada y distribución, algorítmica y masiva, de información falsa, de la "posverdad", que sería la "(d)istorsión deliberada de una realidad, que manipula creencias y emociones con el fin de influir en la opinión pública y en actitudes sociales"».

Faramiñán Fernández-Fígares, Juan Manuel de (2021). «Reflexiones jurídicas acerca de la posverdad». Monograma. Revista Iberoamericana de Cultura y Pensamiento, n. ${ }^{\circ}$ 8, pp. 59-78. doi: 10.36008/monograma.2021.08.1508. http: revistamonograma.com. ISSN: 2603-5839. 
regular al efecto limitando su causa, es decir, determinando límites más claros y condiciones más estrictas para el recabado de datos, ya tenga este por fin la política o el comercio.

En cuanto al derecho punitivo, sería interesante considerar la existencia de un nuevo tipo penal que determine de manera específica la ambigua figura de la posverdad y admitir la necesidad de legislar un sano marco de garantía ética para los nuevos medios de información y difusión de noticias en los que la figura del autor se diluye en una red inextricable de involuntarios e inconscientes colaboradores ${ }^{13}$. Todo ello sin menoscabar derechos ni restringir libertades fundamentales, pero asumiendo la necesidad de separar hoy el derecho a la libertad de expresión —donde cualquier límite supone un menoscabo a la libertad del individuo - del derecho a la información —en donde establecer límites a la información que es suministrada es aún un mal necesario hasta tanto la educación no sea capaz por sí sola de asistirnos a la hora de discernir entre lo que es curativo de lo que es deletéreo-.

\section{Filosofía y posverdad}

Como podemos ver, la cuestión no puede ser resuelta únicamente apelando al paternalismo legislativo del Estado, sino que exige de cada uno un cambio de actitud con relación al mundo y a los demás. No debemos olvidar que el entorno de la posverdad lo hemos creado nosotros mismos y que somos nosotros quienes lo alimentamos diariamente para tener acceso a servicios

13 Para Enrique Cebrián (2018: 36), «En efecto, Internet ha propiciado un cambio absoluto en las formas de comunicación y en el modo de acceder a la información y de actuar con ella. Se han derribado las viejas murallas y hoy [todos] de manera generalizada podemos acceder a medios de comunicación, realizar comentarios, enviar mensajes, crear información, reelaborarla, retuitear la información creada por otros, etc. La antigua verticalidad se ha visto sustituida por una nueva horizontalidad».

Faramiñán Fernández-Fígares, Juan Manuel de (2021). «Reflexiones jurídicas acerca de la posverdad». Monograma. Revista Iberoamericana de Cultura y Pensamiento, n. ${ }^{\circ}$ 8, pp. 59-78. doi: 10.36008/monograma.2021.08.1508. http: revistamonograma.com. ISSN: 2603-5839. 
que no siempre necesitamos, pues el pavor a una sociedad de consumo en la que no todo sea gratuito hace que el argumento comercial cobre valor frente a las restricciones planteadas por las autoridades. Una vez más lo público y lo privado se confrontan olvidando que ambos se sustentan mutuamente en una relación recíproca en la que ninguno de los dos debe ser considerado como un fin en sí mismo.

Ajenos a este enfrentamiento, los seres humanos se centran únicamente en procurarse mayores y mejores bienes o servicios sin atender a los medios, mientras que el Estado aglutina para sí todo el poder posible asumiendo el papel identitario de sus ciudadanos. Pero ni el uno ni los otros son capaces de ver más allá de sus perfiles, por lo que, postergando la función educativa, ambos se han convertido en los esclavos de sus propias creaciones. En este sentido, conviene advertir que una sociedad en la que prima lo privado, es decir, el individualismo, conduce a un tipo de Estado deshumanizado y atomizado, mientras que su carencia conlleva un modelo masificado en el que rápidamente proliferan los sistemas políticos autoritarios. Paradójicamente, en la actualidad, ambas figuran coinciden en un nuevo modelo de ciudadano individualista que, al perseguir exclusivamente su propio beneficio, se va asimilando cada vez más al resto. Un sujeto fácilmente manipulable por un entorno cada vez más mercantilizado y que es incapaz de ver su propio reflejo en quienes le rodean al haberse vuelto transparente y vacío de manera simultánea.

La educación se presenta de este modo como una de las funciones olvidadas, no ya del Estado, sino de la sociedad en su conjunto, pues el problema de fondo se encuentra en la responsabilidad social que los unos tenemos respecto de los otros y que hace que nuestro futuro dependa de aquellas cosas que llevamos 
a cabo en el presente. Debemos por tanto aprender a vencer esa inercia dañina que nos vuelve herméticos al conocimiento, esa especie de resistencia estéril, que nos hace poner en duda permanentemente lo circundante mientras nos aferramos desesperadamente a la inconsistencia de nuestros propios dogmas y creencias. Porque nos hemos acostumbrado a dejarnos llevar por el miedo y las fobias y a dar credibilidad tan solo a lo que nos interesa. Al hacer esto, hemos olvidado que la manera en que interpretamos al mundo, a los demás y a nosotros mismos nos condiciona y que nuestra identidad depende, a menudo, más de nuestro entorno que de nosotros mismos. Esto ha producido una ruptura abrupta en la sociedad, en la que los mecanismos externos de condicionamiento han anulado por completo los internos, abriendo con ello un camino vastísimo para la desinformación y la rumorología.

Desgraciadamente, las causas de la desinformación provienen de los mismos sujetos que las padecen, pues la Caverna platónica (en la que a duras penas podemos distinguirnos los unos de los otros) la hemos construido nosotros mismos, con nuestros prejuicios y debilidades, con esa conducta vil y mezquina que nos vuelve ajenos a lo humano cuando de ello depende nuestro confort. La mentira y el rumor han usurpado el lugar, no ya de la verdad, sino de su fiel amigo y consejero, esto es, de la experiencia, pues siempre será más fácil opinar que profundizar en la esencia misma de la vida, donde el dolor y el placer comparten idéntico lugar ${ }^{14}$. De ahí que se de más crédito a la inmediatez del bulo que a la necesaria decantación de las certezas, que exigen mirar al futuro y medir sus efectos no solo en el ahora sino en el porvenir ${ }^{15}$.

14 Heiner Mercado (2018: 288) define al rumor como uno de los principales vicios a los que se enfrenta la filosofía.

15 Tal vez tengamos que sumarnos a las palabras de Schopenhauer (1961: 175) cuando dice que «cuánto más pertenece un hombre a la posteridad, es decir, a la humanidad en su conjunto, más

Faramiñán Fernández-Fígares, Juan Manuel de (2021). «Reflexiones jurídicas acerca de la posverdad». Monograma. Revista Iberoamericana de Cultura y Pensamiento, n. ${ }^{\circ}$ 8, pp. 59-78. doi: 10.36008/monograma.2021.08.1508. http: revistamonograma.com. ISSN: 2603-5839. 
Ante este estado de las cosas, la filosofía puede resultarnos de utilidad, pues nos enseña a diferenciar aquellas cosas que dependen de nosotros de aquellas otras que no dependen de nosotros y a considerar que no son los acontecimientos los que nos causan perjuicios y dolor, sino la forma en la que actuamos frente a ellos. Porque admirar lo exterior — los bulos, la desinformación, la opinión masiva y la crítica deshumanizada - tan solo puede arrastrarnos al miedo y al desconcierto propio de nuestros deseos cuando son desmedidos. Vibraciones del alma que tienen la capacidad de convertirnos en esclavos de las circunstancias y de aquellos que tienen poder sobre lo que tememos o deseamos.

La filosofía nos permite con ello hacer de nosotros seres humanos libres e independientes, pero al mismo tiempo responsables de la sociedad de la que formamos parte indisoluble. Nos invita a tener una vivencia más plena de nosotros mismos, de los demás y de la naturaleza, y a liberarnos de los miedos, las frustraciones y los complejos que se nos adhieren por una mala comprensión de la vida en comunidad y que nos hacen vivir en una especie de conflicto permanente de todos contra todos. Su eclecticismo derriba las viejas murallas del egocentrismo cultural y nos impulsa a elevar nuestra mirada más allá de los desgastados baluartes de las diferencias raciales, religiosas o culturales. Una ascensión hasta la cima de nosotros mismos donde se intuye un origen común para todos los caminos.

desconocido es de sus contemporáneos. La gente reconoce más fácilmente al hombre que sirve a las circunstancias de su breve hora o al humor del instante al que pertenece y en el que vive y muere».

Faramiñán Fernández-Fígares, Juan Manuel de (2021). «Reflexiones jurídicas acerca de la posverdad». Monograma. Revista Iberoamericana de Cultura y Pensamiento, n. ${ }^{\circ}$ 8, pp. 59-78. doi: 10.36008/monograma.2021.08.1508. http: revistamonograma.com. ISSN: 2603-5839. 


\section{REFERENCIAS BIBLIOGRÁFICAS}

Cebrián, Enrique (2018). «Internet, posverdad y periodismo ciudadano. El derecho a la información en el siglo xxI a la luz de la jurisprudencia del Tribunal Constitucional». En Nogales-Bocio, I. (ed.). Estándares e indicadores para la calidad informativa en los medios digitales. Sevilla: Egregius Ediciones, pp. 33-49.

Corredoira, Loreto y SÁnchez Ferriz, Remedio (2017). «La compleja configuración de un derecho-libertad poliédrico, el Derecho a la información. Referencias históricas». Revista de Derecho Político, n. ${ }^{\circ}$ 99, mayo-agosto, pp. 11-48.

De Faramiñán Fernández-Fígares, Juan Manuel (2019). «Consecuencias jurídicas de la posverdad». Revista Diálogo Filosófico, n. ${ }^{\circ}$ 105, septiembre-diciembre, pp. 353-367.

Mercado-Percia, Heiner (2018). «El dios rumor en la era de la posverdad» [editorial]. Revista Colombiana de Ciencias Sociales, n. ${ }^{\circ}$ (2), julio-diciembre, pp. 274-553. doi: https://doi. org/10.21501/22161201.2837.

Pauner Chulvi, Cristina (2018). «Noticias falsas y libertad de expresión e información. El control de los contenidos informativos en la red». Teoría y Realidad Constitucional, n. ${ }^{\circ}$ 41, pp. 297-318.

Rodríguez-Serrano, Aarón, García-Catalán, Shaila y MarTíN-NúÑEZ, Marta (2019). «Estrategias narrativas audiovisuales de desinformación en YouTube de la nueva extrema derecha europea». El profesional de la información, vol. 28, n. ${ }^{\circ}$ 3, pp. 1-10. doi: https://doi.org/10.3145/epi.2019.may.11.

Rubio NúÑez, Rafael (2018). «Los efectos de la posverdad en la democracia». Revista de Derecho Político, n. 103 , septiembre-diciembre, pp. 191-228.

Schopenhauer, A. (1961). Eudemonología. Madrid: Ediciones Ibéricas. 
Tejerina, O. (2014). Seguridad de Estado y privacidad. Madrid: Editorial Reus.

\section{REFERENCIAS WEB}

https://dle.rae.es/?id=TqpLe0m [Consulta: 15 noviembre 2019]. https://eur-lex.europa.eu/legal-content/ES/TXT/PDF/?uri=CELEX:52017PC0010\&from $=E S$ [Consulta: 15 noviembre 2019].

\section{REFERENCIAS NORMATIVAS}

Constitución española, de 29 de diciembre de 1978 [Consulta: 15 noviembre 2019].

Ley Orgánica 10/1995, de 23 de noviembre, del Código Penal [Consulta: 15 noviembre 2019].

Ley Orgánica de protección civil del derecho al honor, a la intimidad personal y familiar y a la propia imagen de 1982 [Consulta: 15 noviembre 2019].

Reglamento del Parlamento Europeo y del Consejo sobre el respeto de la vida privada y la protección de los datos personales en el sector de las comunicaciones electrónicas (Reglamento sobre la privacidad y las comunicaciones electrónicas o Reglamento ePrivacy) [Consulta: 15 noviembre 2019].

Real Decreto de 24 de julio de 1889 por el que se publica el Código Civil, modificado por el Decreto 1836/1974, de 31 de mayo. Ref. BOE-A-1974-1083 [Consulta: 15 noviembre 2019].

Real Decreto-Ley 12/2018 de 7 de septiembre de seguridad en las redes y sistemas de la información [Consulta: 15 noviembre 2019].

Ley de Seguridad Cibernética [Consulta: 15 noviembre 2019]. 